\title{
Topografia do cone medular da paca (Agouti paca, Linnaeus - 1766)
}

\author{
Alessandra Regina Freixo \\ SCAVONE ${ }^{1}$ \\ Gregório Correa GUIMARÃES² \\ Victor Hugo Vieira \\ RODRIGUES ${ }^{3}$ \\ Tais Harumi de Castro \\ SASAHARA ${ }^{3}$ \\ Márcia Rita Fernandes \\ MACHADO
}

Projeto IC Fapesp processo n. 02/11864-1 Correspondência para:

Márcia Rita Fernandes Machado e-mail:mrfmachd@fcav.unesp.br.

Laboratório de Anatomia do Depto. de Morfologia eFisiologia Animal daFaculdade deCiências Agrárias e Veterinárias, Campus de Jaboticabal, Universidade Estadual Paulista (UNESP)

Recebido para publicação: 26/09/2005 Aprovado para publicação: 13/02/2006

\begin{abstract}
1 - Departamento de Anatomia em Medicina Veterinária da Faculdade de Ciências Agrárias e Veterinárias da Universidade Estadual Paulista, Jaboticabal-SP

2 - Departamento de Morfologia e Fisiologia Animal da Faculdade de Ciências Agrárias e Veterinárias da Universidade Estadual Paulista, Jaboticabal-SP

3 - Departamento de Cirurgia da Faculdade de Medicina Veterinária e Zootecnia da universidade de São Paulo, São Paulo-SP
\end{abstract}

Resumo

Objetivamos neste trabalho determinar a esqueletopia da terminação do cone medular da paca relacionando com as vértebras lombares e sacrais, visando assim estabelecer parâmetros morfométricos e topográficos do cone medular nesta espécie. Para tanto, procedemos à dissecação, mediante incisão, rebatimento da pele, da tela subcutânea e da musculatura da região dorsal à coluna vertebral, com posterior secção e remoção dos arcos vertebrais para melhor visualização da medula espinhal. Após a individualização do cone medular, registramos os aspectos anatômicos de interesse, enfatizando seu início (base) e seu término (ápice) em relação às vértebras, e a partir de então efetuamos suas medidas com o auxílio de paquímetro; visando documentar nossos achados, realizamos fotografias e esquemas dos espécimes estudados.

\section{Introdução}

A espécie Agouti paca, cujos exemplares são popularmente denominados de paca, constitui uma das espécies de roedores originárias da América do Sul, que se distribui nas regiões tropicais, as quais abrangem desde o Sudeste Mexicano até o Nordeste Argentino., Estes animais possuem hábitos noturnos e apresentam porte médio. Os machos medem, aproximadamente, de 60 a $80 \mathrm{~cm}$, enquanto as fêmeas, medem de 55 a $70 \mathrm{~cm}$. Quanto ao peso, chegam a atingir $10 \mathrm{~kg}$. ${ }^{3,4}$ As pacas podem ser criadas com sucesso em cativeiro, sendo sua criação potencialmente viável para a produção de carne, que apresenta sabor característico e é bastante apreciada. ${ }^{2}$

$\mathrm{Um}$ dos motivos pelos quais optamos para a realização deste trabalho, é que a paca não teve sua morfologia totalmente explorada, existindo ainda grandes lacunas quanto à descrição específica de muitos de seus aspectos anatômicos, relevantes ao embasamento prático.

Abordagens a respeito do sistema nervoso tornam-se relevantes, pois o conhecimento da sua morfologia, quanto da sua topografia nas diversas espécies animais, assumem considerável importância na clinica médico-cirurgica veterinária, pois, freqüentemente, são aplicadas injeções de soluções anestésicas no canal vertebral, a fim de se obter o bloqueio de determinadas regiões. Pode-se também puncionar o líquor para exames laboratoriais e ainda facilita a localização de lesões nervosas centrais em níveis vertebrais específicos. ${ }^{5}$

Assim, a anestesia epidural ou peridural, obtida por injeção de anestésicos locais no espaço epidural, que é o espaço compreendido entre a dura máter e o canal vertebral, é a técnica de anestesia regional utilizada com mais freqüência pelos anestesistas devido à sua eficiência, segurança, conveniência e rapidez de aplicação. ${ }^{6}$

O local de aplicação do anestésico no espaço epidural varia conforme a espécie 
animal, de acordo com o local do término da medula espinha, mas a utilização de sítios caudais ao cone medular, torna a técnica de aplicação mais segura, evitando-se, assim, lesões na medula espinhal. ${ }^{7}$

Tendo-se em vista a importância anatômica da região ora descrita, propomonos a estudá-la na paca, objetivando um melhor entendimento da relação vértebromedular e da topografia do cone medular, com intuito de auxiliar possíveis procedimentos anestésicos, que poderão ser utilizados a posteriori nestes animais. Cabe reafirmar a importância do conhecimento da morfologia para esclarecer e identificar características morfofuncionais das espécies estudadas.

\section{Material e Método}

Para esta pesquisa, utilizamos oito pacas adultas, machos e fêmeas, excedentes do plantel do Setor de Animais Silvestres do Departamento de Zootecnia da Faculdade de Ciências Agrárias e Veterinárias, UNESP, Campus de Jaboticabal.

Esses animais foram descartados para a seleção e manutenção do equilíbrio entre machos e fêmeas no criatório estabelecido neste setor e relativamente à ortoeutanásia desses animais, esta foi efetuada associandose, primeiramente uma fase de tranqüilização, na qual foi utilizado azaperone via intramuscular, na dose de $4 \mathrm{mg} / \mathrm{kg}$ de peso corpóreo, seguida a uma fase de sedação, esta mediante a aplicação intramuscular de cloridrato de quetamina $(20 \mathrm{mg} / \mathrm{kg})$ e cloridrato de xilazina $(1,5 \mathrm{mg} / \mathrm{kg})$, ambos na mesma seringa e, como efeito adicional, adotou-se a aplicação de uma mistura de éter (Éter Etílico - C4H10O) e clorofórmio (Trichloromethane - CHC13), em partes iguais, valendo-se de uma máscara convenientemente adaptada à espécie animal, para a conclusão deste processo.

Após o óbito os animais foram encaminhados ao Laboratório de Anatomia desta mesma faculdade, onde foram fixados mediante injeção de solução de formol a $10 \%$, na artéria carótida comum esquerda e mergulhados em cubas contendo essa mesma solução, por no mínimo, 72 horas.

Procedemos a partir de então, a dissecação mediante incisão, rebatimento da pele, da tela subcutânea e da musculatura da região dorsal à coluna vertebral. Posteriormente os arcos vertebrais foram seccionados e retirados para que obtivéssemos melhor visualização da medula espinhal. Após a individualização do cone medular, registramos seus aspectos anatômicos de interesse, enfatizando seu início (base) e seu término (ápice) em relação às vértebras, e a partir de então efetuamos suas mensurações com o auxílio de paquímetro digital "Starrett"cat. No. 727-6/150.

Para a documentação foram realizados esquemas de cada peça estudada e fotografias.

\section{Resultados}

Após a dissecação da região dorsal correspondente ao intervalo entre o tórax e a extremidade distal da cauda, em todos exemplares analisados, verificamos a presença de treze vértebras torácicas, sete vértebras lombares, três vértebras sacrais e sete vértebras coccígeas.

Com relação à topografia do cone medular, constatamos que sua base apresentava relação variando entre a quinta e a sétima vértebras lombares, mas principalmente entre a quinta e sexta vértebra lombar (Figuras 1 e 2). Assim, em um caso $(12,5 \%)$, a base do cone medular situava-se entre a sexta e sétima vértebras lombares; em três observações (37,5\%), localizava-se no nível da sexta vértebra lombar e nas outras quatro preparações $(50 \%)$, posicionava-se entre a quinta e sexta vértebras lombares. Os valores da medida do cone medular e a posição desta estrutura em relação às vértebras, nos animais observados, estão registrados na tabela 1 .

Quanto ao ápice desse cone, nas preparações analisadas foi observada a sua ocorrência variando entre a sétima vértebra lombar e a primeira vértebra sacral. Assim, constatamos em três casos $(37,5 \%)$ sua posição no nível da primeira vértebra sacral 
(esquemas paca1, paca2 e paca5); em uma oportunidade $(12,5 \%)$, esta localização ocorreu entre a sétima vértebra lombar e primeira vértebra sacral (esquema paca3), e,

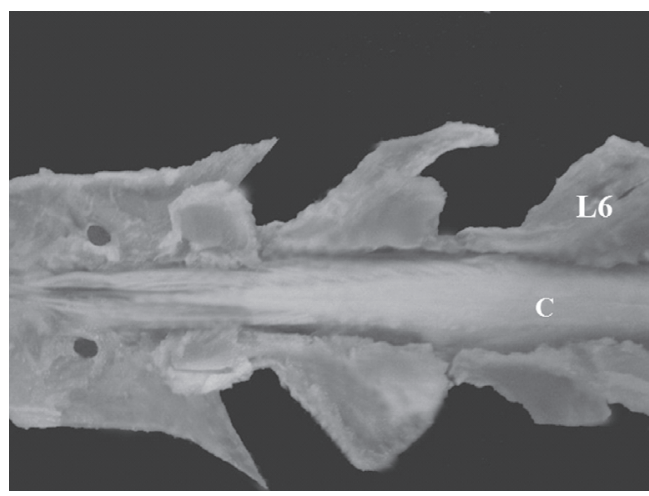

Figura 1 - Fotografia da localização da base (C) do cone medular no nível da sexta (L6) vértebra lombar, em uma paca adulta

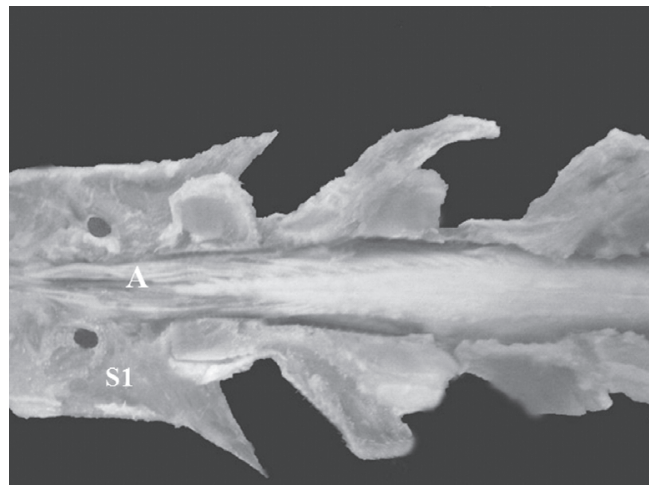

Figura 3 - Fotografia da localização do ápice (A) do cone medular, na altura da primeira vértebra sacral (S1) em uma paca adulta nas outras quatro observações, posicionavase na altura da sétima vértebra lombar (esquemas paca4, paca6, paca7 e paca8 (Figuras 3 e 4).

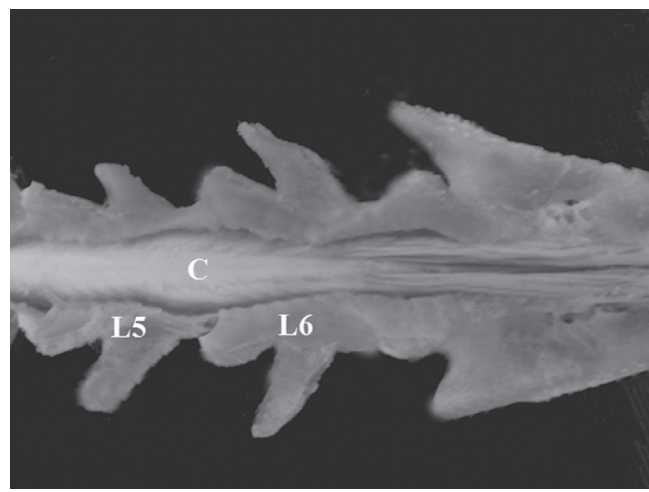

Figura 2 - Fotografia da localização da base (C) do cone medular no nível da quinta (L5) e sexta (L6) vértebras lombares, em uma paca adulta

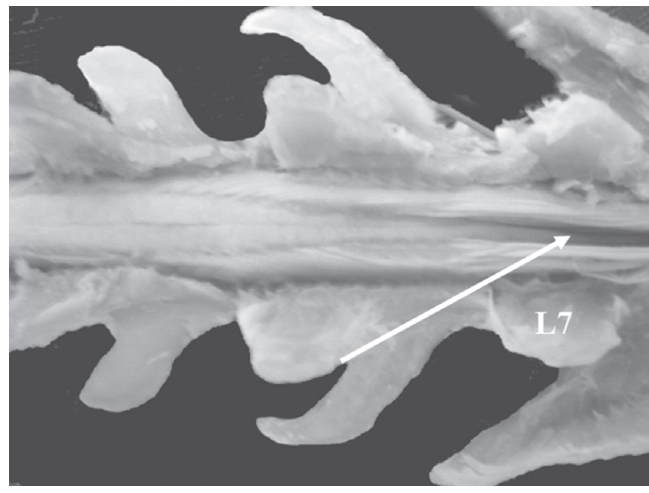

Figura 4 - Fotografia da localização do ápice (seta) do cone medular, na altura da sétima vértebra lombar (L7) em uma paca adulta

Tabela 1 - Relação da base e do ápice do cone medular com a quinta, a sexta e a sétima vértebras lombares $\left(\mathrm{L}_{5}, \mathrm{~L}_{6}\right.$ e $\mathrm{L}_{7}$, respectivamente) e a primeira vértebra sacral $\left(\mathrm{S}_{1}\right)$; comprimento (centímetros - $\mathrm{cm}$ ) do cone medular (CCM) de paca (Agouti paca, Linnaeus - 1766), do Setor de Animais Silvestres do Departamento de Zootecnia da Faculdade de Ciências Agrárias e Veterinárias, UNESP, Campus de Jaboticabal, Jaboticabal, 2005

\begin{tabular}{cccc}
\hline OBSERVAÇÕES & BASE & ÁPICE & C.C.M \\
\hline 1 & entre $\mathrm{L}_{6} \mathrm{eL}_{7}$ & na altura de $\mathrm{S}_{1}$ & 3,25 \\
2 & na altura de $\mathrm{L}_{6}$ & na altura de $\mathrm{S}_{1}$ & 3,60 \\
3 & na altura de $\mathrm{L}_{6}$ & entre $\mathrm{L}_{7} \mathrm{e}_{1}$ & 3,30 \\
4 & entre $\mathrm{L}_{5}$ e $\mathrm{L}_{6}$ & na altura de $\mathrm{L}_{7}$ & 3,40 \\
5 & na altura de $\mathrm{L}_{6}$ & na altura de $\mathrm{S}_{1}$ & 3,50 \\
6 & entre $\mathrm{L}_{5} \mathrm{e} \mathrm{L}_{6}$ & na altura de $\mathrm{L}_{7}$ & 3,32 \\
7 & entre $\mathrm{L}_{5}$ e $\mathrm{L}_{6}$ & na altura de $\mathrm{L}_{7}$ & 3,33 \\
8 & entre $\mathrm{L}_{5}$ e $\mathrm{L}_{6}$ & na altura de $\mathrm{L}_{7}$ & 3,40 \\
\hline
\end{tabular}




\section{Discussão}

A base do cone medular apresentou relação variando entre a quinta (L5) e a sétima (L7) vértebras lombares, e entre os espécimes observados nesta oportunidade, ocorreu, com maior freqüência, o posicionamento do cone medular entre a quinta (L5) e sexta (L6) vértebras lombares, situação esta diferente da encontrada em fetos bovinos azebuados ${ }^{8}$ onde, em média, a base do cone medular estende-se da quarta (L4) à sexta (L6) vértebras lombares; em coelhos $^{9}$, e em ovinos ${ }^{10}$, nas quais esta estrutura encontra-se entre a quinta vértebra lombar (L5) e a primeira vértebra sacral (S1); em caprinos da raça Saanen ${ }^{11}$, onde é delimitada da quinta (L5) à sexta (L6) vértebras lombares; também em eqüinos, onde Manzan et al. ${ }^{12}$ relatam que a base do cone medular nesses animais se encontra desde a quarta vértebra lombar (L4) à segunda vértebra sacral (S2); diferindo dos relatos de Machado et al. ${ }^{13}$ para o lobo-guará e de Amorim et al. ${ }^{14}$ para preguiças Choloepus hoffmanni, espécies, nas quais, o cone medular se encontra no nível da terceira vértebra lombar (L3) e, finalmente, em preguiças da espécie Bradypus variegates para as quais, situam a quarta vértebra lombar (L4) como o limite da base do cone medular.

Quanto ao ápice do cone medular, neste roedor, foi constatado que seu limite variava entre a sétima vértebra lombar (L7) e a primeira vértebra sacral (S1), sendo observado com maior freqüência no nível da sétima vértebra lombar (L7), ocorrência esta, diferente da encontrada em fetos bovinos azebuados ${ }^{8}$, onde o ápice estende-se da terceira (S3) à quarta (S4) vértebras sacrais; em coelhos ${ }^{9}$ onde esta estrutura é delimitada da segunda (S2) à quarta (S4) vértebras sacrais. Os achados atuais são diferentes também dos relatos de Santos e $\mathrm{Lima}^{10}$ para ovinos, e das observações de Santos, Lima e Santana ${ }^{11}$, para caprinos da raça Saanen, pois nestas espécies, o limite dessa estrutura encontra-se entre a primeira (S1) até a terceira (S3) vértebras sacrais; estes achados, na paca, diferem ainda dos relatos de Machado et al. ${ }^{13}$, para o lobo-guará, no qual o ápice do cone medular localiza-se na altura da quinta (L5) à sexta (L6) vértebras lombares; diferindo também dos relatos de Manzan et al. ${ }^{12}$ para os eqüinos, nos quais o ápice do cone medular situa-se desde a terceira vértebra sacral (S3) à primeira vértebra coccígea (C1) e, finalmente, a situação observada nesta oportunidade também é diferente da relatada por Silva et al. ${ }^{14}$, que para preguiças da espécie Choloepus hoffmanni, o ápice do cone medular é, determinado pela quarta vértebra lombar (L4) e para preguiças da espécie Bradypus variegates, delimitado pela primeira vértebra sacral (S1).

Da mesma forma que observado por, Santos, Lima e Santana. ${ }^{11}$ para a base do cone medular, no ápice dessa estrutura na paca, ocorrem variações em relação às vértebras lombares e sacrais, não denotando nesta oportunidade, situação relacionada às vértebras coccígeas tal qual se refere Manzan et al. ${ }^{12}$, para eqüinos.

Com relação ao comprimento médio do cone medular, inicialmente, da mesma forma que Santos, Lima e Santana ${ }^{9}$, Santos, Lima e Santana ${ }^{11}$, Machado et al. ${ }^{13}$, e foi estabelecido que, seu início correspondia à sua base e seu final era determinado por seu ápice.

No que se refere ao valor médio obtido do comprimento do cone medular da paca $(3,39 \mathrm{~cm})$, este se apresentou inferior aos encontrados em coelhos $4,51 \mathrm{~cm}^{9} \mathrm{em}$ caprinos $3,44 \mathrm{~cm}^{11}$; no lobo-guará $6,5 \mathrm{~cm}^{13} \mathrm{e}$ $\mathrm{em}$ fetos eqüinos $4,2 \mathrm{~cm}$.

\section{Conclusão}

Considerando-se que a extensão do cone medular da paca varia de L5 a S1, sugere-se que a anestesia epidural, nesses animais, seja realizada na região sacrococcígea. 


\title{
Topography of the medullar cone in the paca (Agouti paca, Linnaeus - 1766)
}

\begin{abstract}
We object in this work to determine the skeleton sintopy of the medular cone termination of the paca relating to the lumbar and sacral vertebrae, thus aiming at establishing morphometric and topographical parameters of the medular cone in this specie. We accomplished the dissection through skin incision, subcutaneous divulsion and dissection of the vertebral column dorsal region musculature, sectioning and removing the vertebrae arcs for better visualization of the spinal medulla. After the individualization of the medular cone, we registered the anatomical aspects of interest, emphasizing the basis and its apex in relation to the vertebrae, following the measuring of the region using a caliper rule; photographs and schematic drawing were made to register the findings of studied specimens.
\end{abstract}

Key words:

Anatomy Medulla. Paca.

\section{Referências}

1 EISENBERG, J. F.; REDFORD, K. H. Mammals of the neotropics. London: The University of Chicago Press, 1989.

2 PÉREZ, E. M. Mammalian Species - Agouti paca. The American Society of Mammalogists, n. 404, p. 1-7, 1992.

3 MONDOLFI, E. La laca o Paca. Defensa de la naturaleza. Caracas, v. 2, n. 5, p. 4-16, 1972.

4 BENTTI, S.B. Roedores da América Tropical. Natura, Caracas, n. 70, p. 40- 44, 1981.

5 DYCE, J. M.; SACK, W. O.; WENSING, C. I. G.; Tratado de anatomia veterinária. Rio de Janeiro: Guanabara Koogan, 1997. p. 238-240.

6 FANTONI, D. T.; CORTOPASSI, S. R. G. Anestesia em cães e gatos. 2 ed. São Paulo: ROCA, 2002.

7 HILBERY, A. D. R. Manual de anestesia de los pequeños animales. Zaragoza: Acribia, 1992. p. $72-75$.

8 QUEIROZ, D. N.; SILVA, F. O. C.; SEVERINO, R. S.; DRUMMOND, S. S.; SANTOS, A. L. Q.; LIMA, E. M. M. Topografia do cone medular em fetos de bovinos sem raça definida. In: SIMPOSIO CIENTÍFICO INTEGRADO DA AGRONOMIA E VETERINARIA DA UNIVERSIDADE
FEDERAL DE UBERLANDIA, 4., 1999. Anais...

9 SANTOS, A. L. Q.; LIMA, E. M. M.; SANTANA, M. I. S. Comprimento da medula espinhal e topografia do cone medular em coelhos (Oryctolagus cuniculus) In: ENCONTRO DE INICIAÇÃO CIENTÍFICA, 7, 1998, Uberlândia. Anais...

10 SANTOS, A. L. Q.; LIMA, E. M. M. Topografia do cone medular em ovinos sem raça definida (Ovis aries) Ars Veterinária. v.16, p. 154-157, 2000.

11 SANTOS, A. L. Q. LIMA, E. M. M.; SANTANA, M. I. S. Topografia do cone medular em caprinos da raça Saanen Arquivo Ciências Veterinárias Zoologia. UNIPAR, v. 4, n. 1, p. 25-29, 2001.

12 MANZAN, R.M. et al. Esqueletopia do cone medular em fetos de equinos, Veterinária Notícias, v. 9, p.18, 2003.

13 MACHADO, V. M. et al. Topografia do cone medular no lobo-guará, Revista Brasileira de Ciência Veterinária. v. 9, p. 107-109, 2002.

14 SILVA, D. R. et al. Topografia do cone medular da preguiça, Choloeppus hoffmanni PETERS, 1865 e Bradypus variegatus SCHINZ, 1825. In: CONGRESSO DE INICIAÇÃO CIENTíFICA, 2., 2002, Recife, Anais... Recife: Pro-Reitoria de Pesquisa e de Pós-Graduação da Universidade Federal Rural de Pernambuco, 2002. p. 527-528. 